Supporting Information for

\title{
Near-Infrared Small Molecule as a Specific Fluorescent Probe for Ultrasensitive Recognition of Antiparallel Human Telomere G-Quadruplexes
}

Ming Jin ${ }^{a}$, Jing Li ${ }^{a}$, Yang Chen ${ }^{a}$, Jie Zhao ${ }^{a}$, Jiahui Zhang ${ }^{a}$, Zhen Zhang ${ }^{a}$, Peiyao Du ${ }^{a}$, Libing Zhang ${ }^{* a}$ and Xiaoquan $\mathrm{Lu} * b$

a Tianjin Key Laboratory of Molecular Optoelectronic, Department of Chemistry, Tianjin University, Tianjin 300072, People's Republic of China

${ }^{\mathrm{b}}$ Key Laboratory of Bioelectrochemistry and Environmental Analysis of Gansu Province, College of Chemistry and Chemical Engineering, Northwest Normal University, Lanzhou 730070, People's Republic of China

*Corresponding Author

E-mail addresses: luxq@nwnu.edu.cn (Xiaoquan Lu); libing.zhang@tju.edu.cn (Libing Zhang) 


\section{EXPERIMENTAL SECTION}

\section{Materials}

Dnase I and RnaseA were purchased from Sangon Biotech Co. Ltd. (Shanghai, China). 4chloro-2-methylquinolin, 2-methybenzothiazole, sulfolane, potassium iodide, 4-methl-piperidine were purchased from Energy Chemical. 2,2'-azino-bis(3-ethylbenzothiazoline-6-sulfonicacid) diammonium salt (ABTS) was purchased from Heowns Biochem Technologies Co. Ltd. (Tianjin, China). Iodomethane was purchased from 3A Chemicals. Hemin was purchased from Solarbio Science \& Technology Co. Ltd. Mito Deep Red was purchased from Thermo Fisher Scientific. 9-Julolidinecarboxaldehyde was purchased from Shanghai Meryer Chemical. Stock solutions of TOVJ (10.0 mM) were prepared in DMSO.

\section{Instruments}

Electropray ionization mass spectrometry (ESI-MS) was recorded on an LC-MS 2010A system (Shimadzu). High-resolution MS was conducted on a Bruker Daltonics Flex-Analysis spectrometer. 1H nuclear magnetic resonance (NMR) spectra were measured on AVANCE III 400 M nuclear magnetic resonance spectrometer (Bruker). Fluorescence spectra were carried out using an FS5 fluorescence spectrofluorometer. Ultraviolet-visible (UV-vis) absorbance spectra were collected on UV756CRT (China), SpectraMax M5 plate reader (Molecular Devices, Sunnyvale, CA) and Shimadzu UV-3600 Plus. Circular dichroism spectra were characterized by a JASCO J810 circular dichroism spectropolarimeter. Fluorescence images were recorded on an FV3000IX83 confocal microscope (Olympus).

\section{Synthesis of intermediates 1-3 1}

4-chloro-1,2-dimethylquinolin-1-ium Iodide (1). 4-chloro-2-methylquinolin (0.50 g, 2.80 $\mathrm{mmol})$, iodomethane $(1.05 \mathrm{~mL}, 16.85 \mathrm{mmol})$ was dissolved in sulfolane $(10.0 \mathrm{~mL})$, and the reaction mixture was heated to $70{ }^{\circ} \mathrm{C}$ and stirred for $15 \mathrm{~h}$, then cooling to room temperature, anhydrous ether was added to the mixture, the solids were collected by suction filtration, wash three times with anhydrous ether, dried in vacuo. MS (ESI) $m / z$ : calcd for $\mathrm{C}_{11} \mathrm{H}_{11} \mathrm{ClN}^{+}[\mathrm{M}]^{+} 192.1$, found 192.1. 
1,2-dimethylbenzothiazol-1-ium Iodide (2). 2-methybenzothiazole (0.50 g, $3.36 \mathrm{mmol})$, iodomethane $(0.75 \mathrm{~mL}, 12.0 \mathrm{mmol})$ was dissolved in dichloromethane $(15 \mathrm{ml})$ and refluxed at $40{ }^{\circ} \mathrm{C}$ for $18 \mathrm{~h}$. After cooling to room temperature, the solid was filtered and washed with anhydrous ether, and vacuum-dried to give compound 2. MS (ESI) $m / z$ : calcd for $\mathrm{C}_{9} \mathrm{H}_{10} \mathrm{NS}^{+}[\mathrm{M}]^{+} 164.1$, found 164.1.

(Z)-1,2-dimethyl-4-((3-methylbenzo[d]thiazol-2(3H)-ylidene)methyl)quinolin-1-ium (3). Compound 1 (0.75 g, $2.40 \mathrm{mmol})$, Compound $2(0.75 \mathrm{~g}, 2.58 \mathrm{mmol})$ and aqueous sodium bicarbonate solution $(0.5 \mathrm{~mol} / \mathrm{L}, 3.0 \mathrm{~mL})$ were dissolved in $10 \mathrm{~mL}$ anhydrous methanol and the reaction mixture was stirred at room temperature for $1 \mathrm{~h}$. Next, $6 \mathrm{ml}$ of saturated potassium iodide solution was added to the reaction solution, and continue stirred for about $15 \mathrm{~min}$. The solid obtained was collected via vacuum filtration, washed with water and acetone and vacuum-dried to give compound 3. MS (ESI) $m / z$ : calcd for $\mathrm{C}_{20} \mathrm{H}_{19} \mathrm{~N}_{2} \mathrm{~S}^{+}[\mathrm{M}]^{+} 319.1$, found 319.1

\section{G4-FID Assay}

The G4-FID assay was designed as follows: $2.5 \mu \mathrm{M}$ pre-folded DNA target was mixed with thiazole orange ( $5 \mu \mathrm{M}$ for $\mathrm{EAD}, 7.5 \mu \mathrm{M}$ for ds26). TOVJ addition (from 0.5 to 10 equivalents) was followed by a 60 min equilibration period, after which the fluorescence spectrum was recorded. The percentage of displacement was calculated as follows: TO displacement $(\%)=100-\left[\left(\mathrm{F}_{\mathrm{A}} /\right.\right.$ $\left.F_{A 0}\right) \times 100$ ], where $F_{A}$ and $F_{A 0}$ stand for the fluorescence emission area of TO bound to DNA after TOVJ addition and $\mathrm{F}_{\mathrm{A} 0}$ before TOVJ addition (area measured from 510 to $750 \mathrm{~nm}, \lambda \mathrm{ex}=501 \mathrm{~nm}$ ).

\section{Competition Equilibrium Dialysis Assays}

Competition equilibrium dialysis assays were carried out according to previous reports. ${ }^{2}$ The dialysis units (Float-A-Lyzer G2 Dialysis Device, Biotech, CE, MWCO-molecular weight cut off: 3.5-5 kD), each containing a $250 \mu \mathrm{L}$ volume of different DNA $(75 \mu \mathrm{M})$ were placed in a beaker containing $200 \mathrm{~mL}$ TOVJ solution $(1 \mu \mathrm{M})$. The solvent used in the experiments was Tris- $\mathrm{HCl}$ buffer $(10 \mathrm{mM}, \mathrm{pH}=7.4)$ containing $0.1 \mathrm{mM}$ EDTA and $100 \mathrm{mM} \mathrm{NaCl}$ or $\mathrm{KCl}$. The beaker was covered with parafilm and wrapped in aluminum foil, and its contents were allowed to equilibrate with continuous stirring for $24 \mathrm{~h}$ at room temperature. After the dialysis, $100 \mu \mathrm{L}$ of each $\mathrm{G} 4$ sample 
was transferred to a 96-well clear flat bottom UV-transparent microplate and a $10.0 \%(\mathrm{w} / \mathrm{v})$ stock solution of surfactant (SDS or Triton X-100) was added to give a final concentration of $1.0 \%(\mathrm{w} / \mathrm{v})$. Two hours later, the absorbance of each sample at $467 \mathrm{~nm}$ was recorded on a SpectraMax M5 microplate analyzer to determine the total concentration $\left(\mathrm{C}_{\mathrm{t}}\right)$ of TOVJ in each sample. The absorbance of TOVJ in dialysis solution was determined by the same method to determine the concentration of free TOVJ $\left(\mathrm{C}_{\mathrm{f}}\right)$. The concentration of bound ligand $\left(\mathrm{C}_{b}\right)$ was calculated by

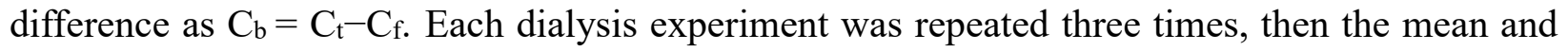
standard deviation were calculated. The competition equilibrium dialysis data were then used to calculate the apparent equilibrium dissociation constants of TOVJ with G4s using the equation $\mathrm{K}_{\mathrm{d}}$ $=\left(\mathrm{C}_{\mathrm{f}}\right)\left(\mathrm{S}_{\text {total }}-\mathrm{C}_{\mathrm{b}}\right) / \mathrm{C}_{\mathrm{b}}$, where the $\mathrm{S}_{\text {total }}$ is the total $\mathrm{G} 4$ concentration $(75 \mu \mathrm{M}){ }^{2}$

\section{NMR}

Parallel G4 (c-myc) $(150 \mu \mathrm{M})$ was solved in Tris-HCl buffer with $100 \mathrm{mM} \mathrm{KCl}$ in $10 \% 10 \%$ $\mathrm{D}_{2} \mathrm{O} / 90 \% \mathrm{H}_{2} \mathrm{O}$. All NMR spectra were recorded on a VARIAN INOVA 500MHz spectrometer.

\section{Molecular Docking}

The Lamarckian genetic algorithm of AutoDock 4.2 software was used for molecular docking. The structure files of Parallel 22AG and Anti-Parallel 22AG are from Protein Data Bank (PDB ID: 3T5E and 143D). The crystal structure of the G-quadruplex and the target small molecule was optimized by AutoDockTools software. The $\sigma$ bonds between atoms in the TOVJ molecule were all set as rotatable bonds, and the G4s were regarded as a rigid structure for semi-flexible docking. During the docking process, a $120 \times 120 \times 120$ step docking square box (with a step length of $0.375 \AA$ ) was set on the G4 binding site, and TOVJ was docked 200 times independently at the binding site. Perform cluster analysis on 200 docking results, and select the binding conformation with the best docking score (the smallest score) from the optimal cluster to determine the binding site and binding mode of the G4s and theTOVJ. 


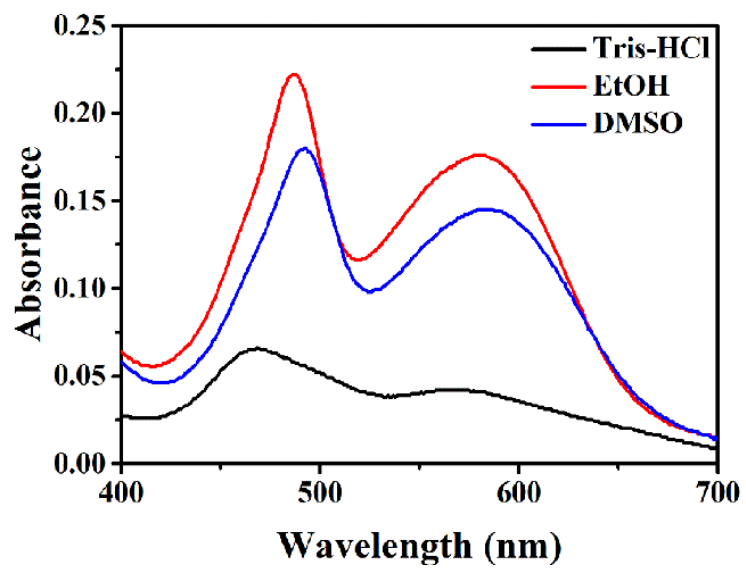

Figure S1. Absorption spectra of TOVJ $(5 \mu \mathrm{M})$ in Tris-HCl buffer, EtOH and DMSO.

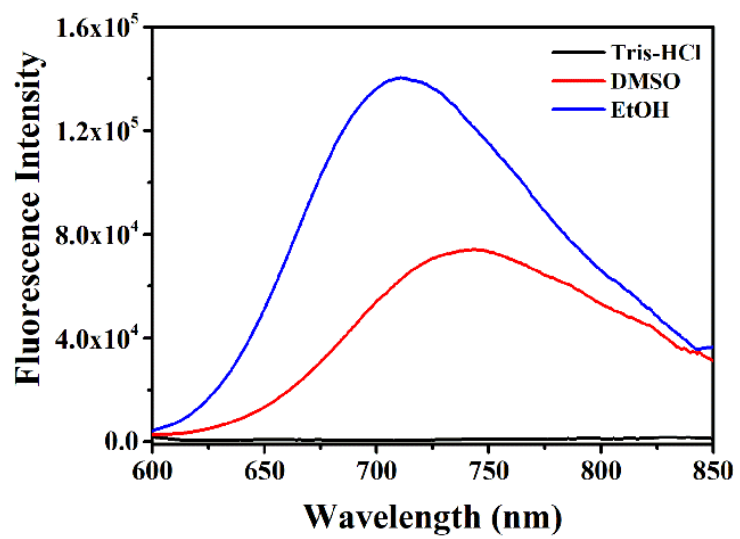

Figure S2. Fluorescence spectra of TOVJ $(5 \mu \mathrm{M})$ in Tris-HCl buffer, EtOH and DMSO. $(\lambda \mathrm{ex}=492 \mathrm{~nm})$.

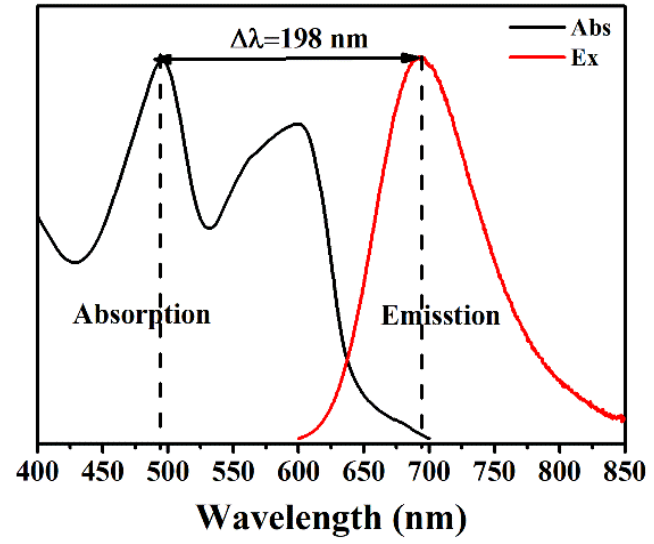

Figure S3. Absorption and emission spectra of TOVJ $(5 \mu \mathrm{M})$ in the presence of Hum24 $(10 \mu \mathrm{M})$. 


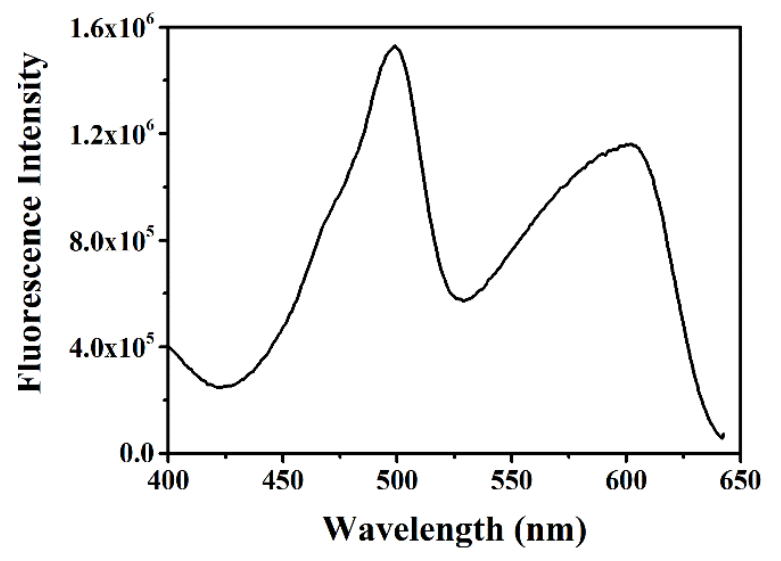

Figure S4. Excitation spectrum of TOVJ $(5 \mu \mathrm{M})$ in the presence of Hum24 $(10 \mu \mathrm{M})$.

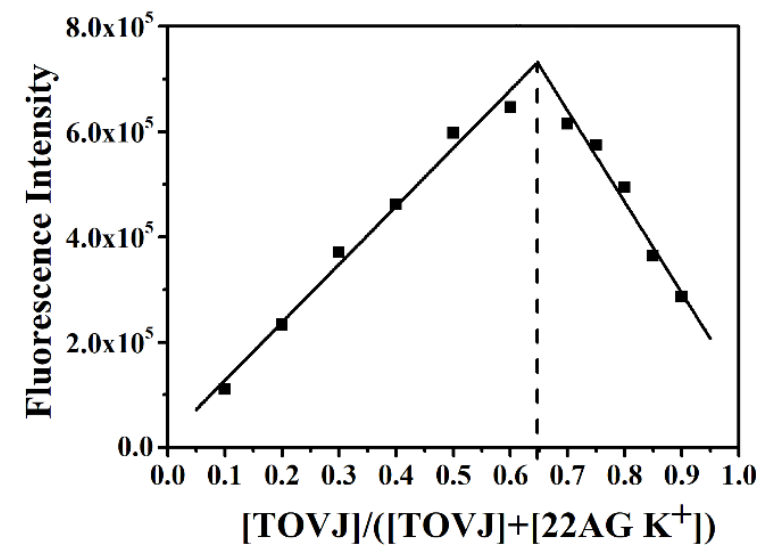

Figure S5. The Job's plot analysis for the binding stoichiometry of TOVJ to $22 \mathrm{AG} \mathrm{K}^{+}$. The total concentration of TOVJ and $22 \mathrm{AG} \mathrm{K}^{+}$is $10 \mu \mathrm{M} ; \lambda \mathrm{ex} / \mathrm{em}=492 / 694 \mathrm{~nm}$.

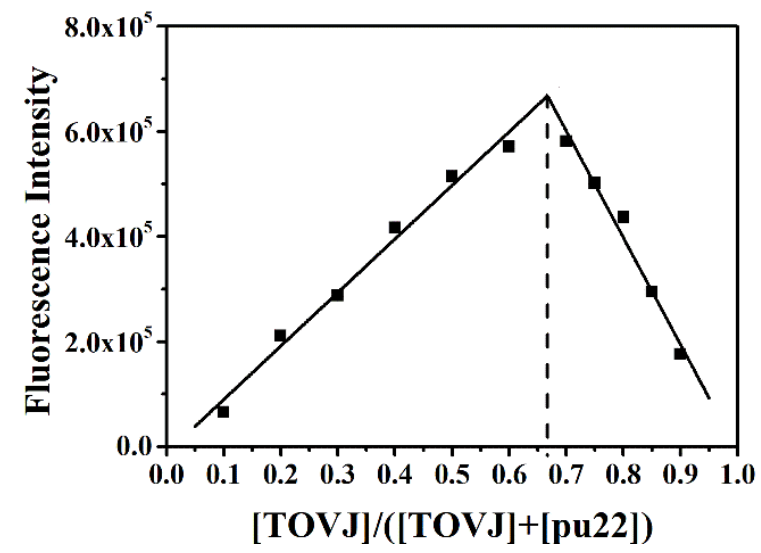

Figure S6. The Job's plot analysis for the binding stoichiometry of TOVJ to pu22. The total concentration of TOVJ and pu22 is $10 \mu \mathrm{M}$; $\lambda$ ex/em $=492 / 694 \mathrm{~nm}$. 


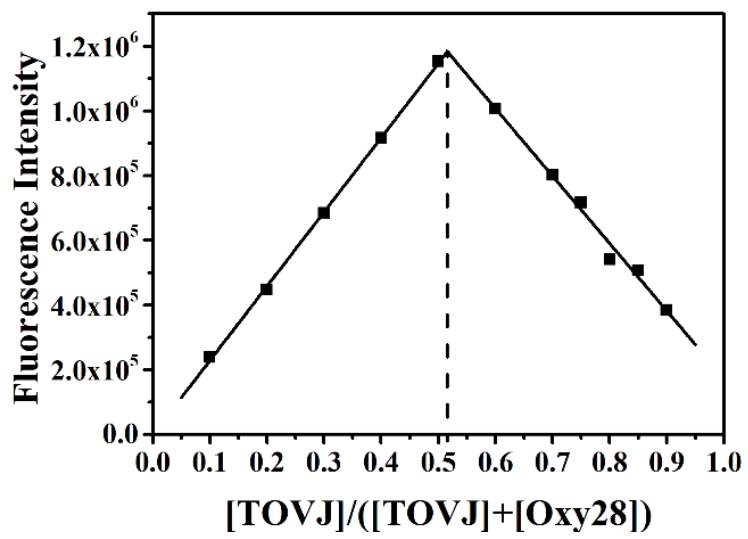

Figure S7. The Job's plot analysis for the binding stoichiometry of TOVJ to Oxy28. The total concentration of TOVJ and Oxy28 is $10 \mu \mathrm{M}$; $\lambda$ ex/em $=492 / 694 \mathrm{~nm}$.

TOVJ: c-myc
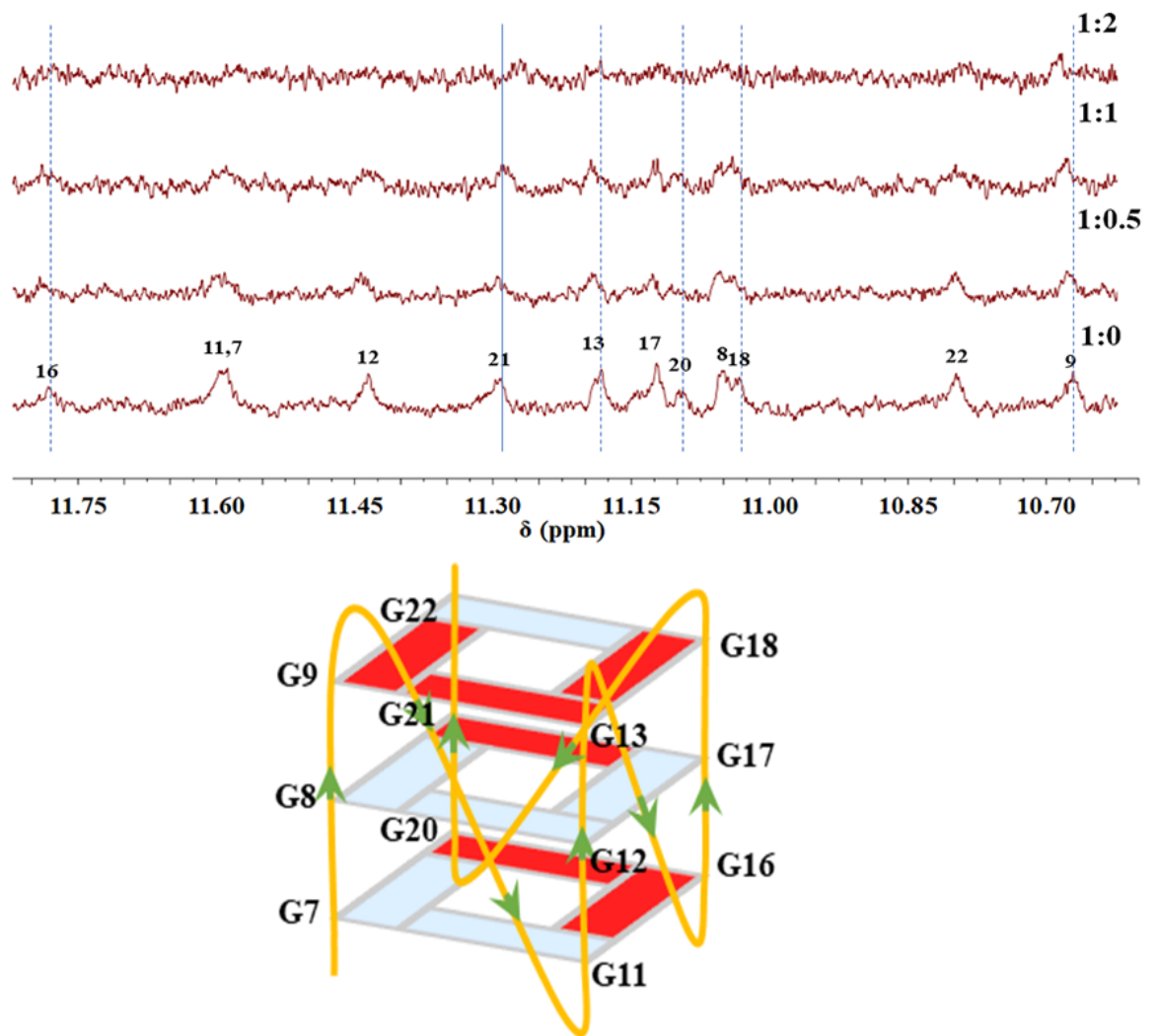

Figure S8. ${ }^{1} \mathrm{H}$ NMR spectra of $200 \mu \mathrm{M}$ c-myc (5'-TGAGGGTGGGGAGGGTGGGGAA-3') recorded in the presence of various concentrations of TOVJ. 


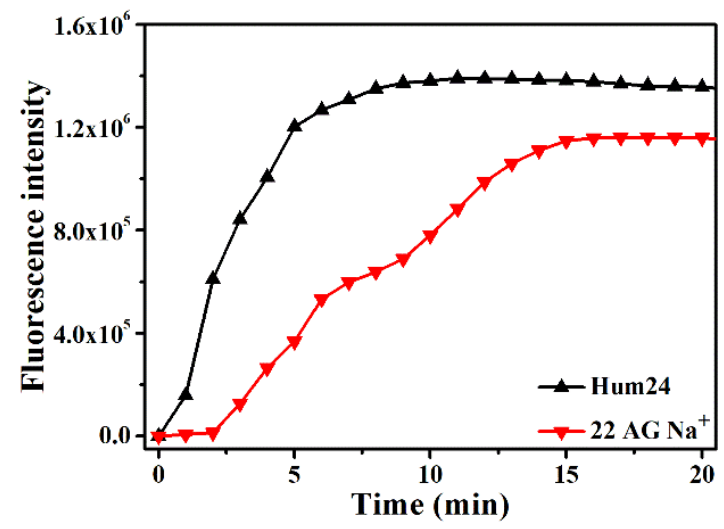

Figure S9. Time-dependent fluorescence intensity changes at $692 \mathrm{~nm}$ of TOVJ $(5 \mu \mathrm{M})$ in presence of Hum 24 or $22 \mathrm{AG} \mathrm{Na}^{+}(10 \mu \mathrm{M})$ in Tris-HCl buffer $(10 \mathrm{mM}, \mathrm{pH}=7.4)$.

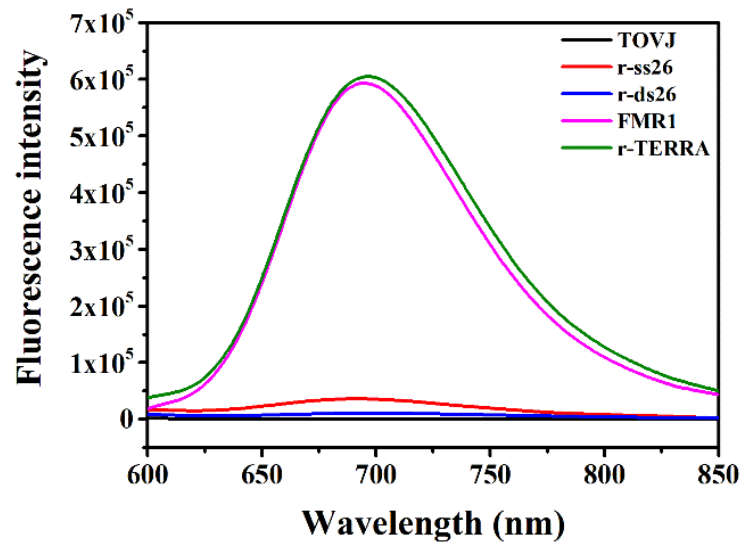

Figure S10. Fluorescence spectra of TOVJ $(5 \mu \mathrm{M})$ with or without different RNA $(10 \mu \mathrm{M})$ in Tris-HCl buffer $(10 \mathrm{mM}, \mathrm{pH}=7.4), \lambda_{\mathrm{ex}}=492 \mathrm{~nm}$. 
Table S1. Apparent equilibrium dissociation constants $\left(\mathrm{K}_{\mathrm{d}}\right)$ of TOVJ with different G4s measured with equilibrium dialysis.

$\begin{array}{cc}\text { DNA } & \mathbf{K}_{\mathbf{d}}\left(\mathbf{1 0}^{-\mathbf{6}} \mathbf{M}\right) \\ \mathrm{ds} 26 & 62.3 \pm 9.756 \\ \operatorname{pu} 22 & 0.819 \pm 0.113 \\ \text { c-myc } & 1.087 \pm 0.195 \\ \text { EAD } & 1.212 \pm 0.247 \\ 22 \mathrm{AG} \mathrm{K} \mathrm{K}^{+} & 0.583 \pm 0.121 \\ 22 \mathrm{AG} \mathrm{Na}{ }^{+} & 0.227 \pm 0.027 \\ \text { Hum2 } 24^{\text {Oxy28 }} & 0.198 \pm 0.039 \\ \end{array}$

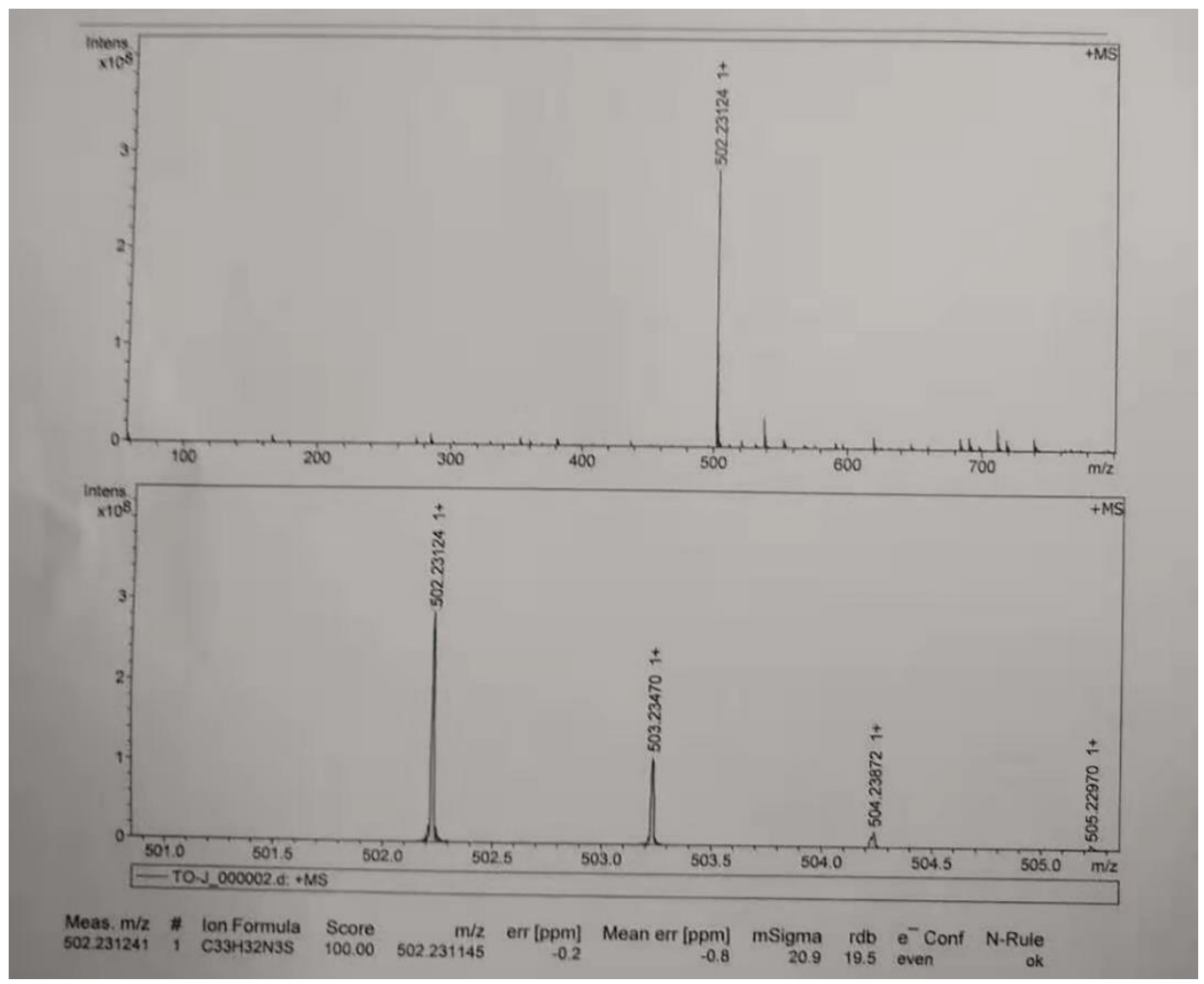

Figure S8. HRMS (ESI-TOF) spectra of TOVJ 


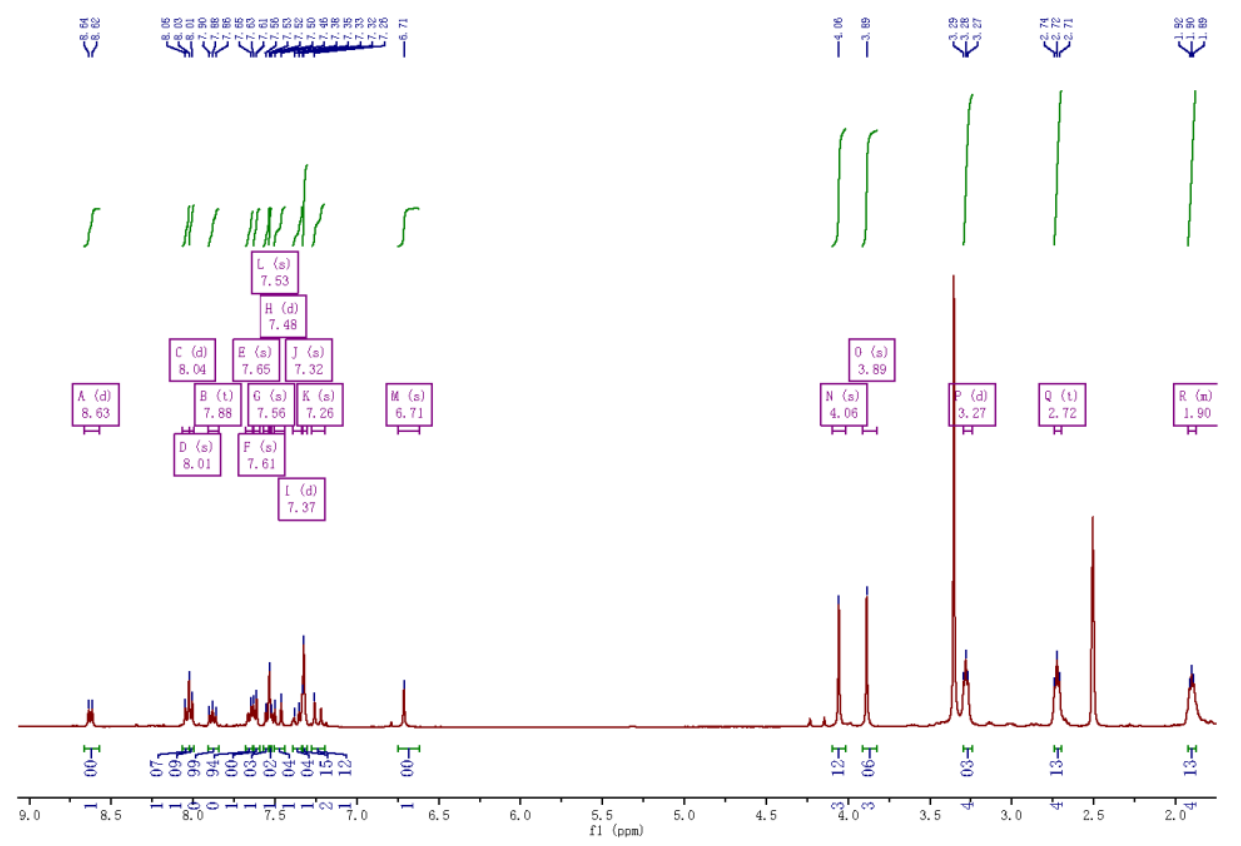

Figure S9. ${ }^{1} \mathrm{H}$ NMR spectra of TOVJ (400 MHz deuterated DMSO-d6)

\section{References:}

(1) Lu, Y. J.; Deng, Q.; Hou, J. Q.; Hu, D. P.; Chow, C. F. Molecular Engineering of Thiazole Orange Dye: Change of Fluorescent Signaling from Universal to Specific upon Binding with Nucleic Acids in Bioassay. ACS Chem. Biol. 2016, 11, 1019.

(2) Chaires, J. Competition Dialysis: An Assay to Measure the Structural Selectivity of DrugNucleic Acid Interactions. Curr. Med. Chem-Anti-Cancer Agents 2005, 5, 339-352. 